season of Landsat 4 and 5 acquisition. The majority of the scenes have been acquired by two major projects: the West German Institut für Angewandte Geodäsie project to acquire data from the Ronne Ice Shelf area to the Greenwich meridian, and the USGS project to acquire data of coastal Antarctica and the inland boundary of the ice shelves, for use by the Scientific Committee on Antarctic Research (SCAR) community. Landsat 4 and 5 have different orbital parameters from Landsat 1,2 , and 3 . As a result Landsat 4 and 5 imagery have different areal coverage. The data also have been archived differently. While the Landsat 1,2 , and 3 data exist in film format, many Landsat 4 and 5 TM images exist only as high-density digital tapes, and, as a result, the scenes cannot be examined and evaluated before purchase. Computer evaluation of the Landsat 4 and 5 data indicate that about 1350 or about $30 \%$ of the images have $10 \%$ cloud cover or less. However, it is difficult for automatic systems or those unfamiliar with the area to discriminate between clouds and snow. Based on a sampling of the data, it is more likely that $10-15 \%$, or about 500 scenes, are of good quality. Those scenes which have been examined and evaluated as part of the SCAR cooperative acquisition project and are known to be of good quality are plotted and compared with the earlier Landsat data. The combined plot gives accurate and reliable information on the location of good quality Landsat 1-5 data of Antarctica.

More than 7000 Sojuzkarta scenes have been collected over Antarctica since 1976. The most useful data consist of photography from the KATE-200 system ( $20 \mathrm{~m}$ resolution) and the KFA-1000 system ( $6 \mathrm{~m}$ resolution). The data have been plotted by the U.S. Geological Survey and will soon be available as an open-file report. Those scenes which have been evaluated as having $10 \%$ cloud cover or less are plotted separately and overlaid on the Landsat plots. Scenes which have been examined are excellent, but an insufficient number of scenes have been inspected to evaluate the accuracy of the cloud cover estimation.

The Système Probatoire d'Observation de la Terre (SPOT) was launched in 1986 and has acquired more than 1200 scenes of Antarctica. SPOT data consist of multispectral $(20 \mathrm{~m}$ resolution) and panchromatic ( $10 \mathrm{~m}$ resolution) photographic or digital imagery. SPOT also possesses a mechanical plane mirror which permits off-nadir imaging and the generation of stereoscopic images. The locations of these scenes are now being plotted by the U.S. Geological Survey. Scenes with $10 \%$ cloud cover or less will be combined with Landsat and Sojuzkarta data to provide an accurate summary of the availability and coverage of highquality satellite data of Antarctica.

\title{
POTENTIAL FOR BASAL MELTING UNDER THE SUMMIT CORING SITE, CENTRAL GREENLAND
}

\author{
(Abstract)
}

by

John Firestone, Ed Waddington and Jim Cunningham

(Geophysics Program AK-50, University of Washington, Seattle, WA 98195, U.S.A.)

The climatic record from Greenland boreholes is likely to extend well beyond the last interglacial only if the basal ice near the drilling sites has never reached its pressure melting point $\left(-2^{\circ} \mathrm{C}\right)$. A simplified one-dimensional analysis (Paterson and Waddington, 1986) suggested that this would be true at Crête, Greenland, if the geothermal flux was less than $48 \mathrm{~mW} \mathrm{~m}^{-2}$. In that study, the vertical velocity pattern for an isothermal ice sheet was used. We have repeated the Crête calculations using the vertical velocity pattern derived by a finite element analysis. Using this temperaturedependent velocity pattern lowered the basal temperature by about $3{ }^{\circ} \mathrm{C}$

We have carried out a similar analysis for the Summit coring site further north on the Greenland ice divide. Here we find that the basal ice does not melt if the geothermal flux is less than $54 \mathrm{~mW} \mathrm{~m}^{-2}$, using the same mass balance and surface temperature histories as the previous study. We are repeating these one-dimensional calculations with more recently compiled histories and plan to present results from a full two-dimensional temperature model that includes a full two-dimensional temperature model that in the one-dimensional models. Using two dimensions, we will more realistically incorporate the special ice-flow patterns found at divides (e.g. Raymond, 1983; Dahl-Jensen, 1989). In steady-state flow models these patterns lead to significant horizontal temperature gradients and a "hot spot" beneath an ice divide (Paterson and Waddington, 1986). In addition, we will more accurately determine the transient effects on basal temperature resulting from the interaction of these flow patterns and the changing climate. Our discussion will include sensitivity to geothermal heat flux, ice thickness and paleoenvironmental history.

\section{REFERENCES}

Dahl-Jensen, D. 1989. Steady thermomechanical flow along two-dimensional flow lines in large grounded ice sheets. J. Geophys. Res., 94(B4), 10,355-10,362.

Paterson, W.S.B. and E.D. Waddington. 1986. Estimated basal ice temperature at Crête, Greenland, throughout a glacial cycle. Cold Reg. Sci. Technol., 12(1), 99-102.

Raymond, C.F. 1983. Deformation in the vicinity of ice divides. J. Glaciol., 29(103), 357-373. 